\title{
La frontera mercantil del turismo y su dinámica de apropiación y capitalización de la arena como recurso natural
}

The mercantile frontier of tourism and its dynamics of appropriation and capitalization of sand as a natural resource

Alejandro Escalera Briceño

Universidad Intercultural del Estado de Puebla - México

Huehuetla, México

alejandro.escalera@uiep.edu.mx

Alejandro Palafox Muñoz †

Universidad de Quintana Roo - México

Cozumel, México

palafox@uqroo.edu.mx

\section{RESUMEN}

En el presente artículo se expone una crítica referente a la extracción de arena que ocurrió en el Banco Punta Norte en la isla Cozumel y La Ollita II en Isla Mujeres en el Caribe mexicano. Estos hechos tienen especial relevancia para evidenciar cómo el capitalismo se apropia de la materia prima (recursos naturales) de forma gratuita o barata. Esta dinámica se produce bajo la frontera mercantil del turismo, la cual consiste en la apropiación y capitalización de la arena para solucionar la erosión de las costas, principalmente de la zona hotelera de Cancún, bastión de la actividad turística en México, presenciando el robo del subsuelo a través de la acumulación por desposesión para el fortalecimiento de la dinámica capitalista. De este modo, el artículo busca contribuir a los estudios críticos del turismo, especialmente en los conflictos socioambientales.

Palabras clave: Frontera mercantil del turismo; Cuatro Baratos; materia prima; arena; Caribe mexicano

\section{ABSTRACT}

In the present paper, criticism is presented regarding the extraction of sand that occurred in the Punta Norte Bank on Cozumel Island and La Ollita II on Isla Mujeres in the Mexican Caribbean, these facts have special attention to show how capitalism appropriates raw material (natural resources) for free or cheap. This dynamic occurs under the commercial border of tourism, which consists of the appropriation and capitalization of the sand to solve the erosion of the coasts, mainly in the hotel zone of Cancun, a bastion of activity in Mexico, witnessing the theft of the subsoil through accumulation by dispossession for the strengthening of capitalist dynamics. In this way, the article seeks to contribute to critical studies of tourism, especially in socio-environmental conflicts.

Keywords: Commodity frontier of tourism; four cheaps; raw material; sand; Mexican Caribbean. 


\section{INTRODUCCIÓN}

A la luz de las aportaciones de la ecología política se ha evidenciado el extractivismo de los recursos naturales. Los países del Sur Global cada vez son más asediados por las transnacionales por sus materias primas. Para Gudynas, el extractivismo se refiere a "un conjunto particular de apropiaciones de recursos naturales, además, su característica son los grandes volúmenes removidos y la alta intensidad de su extracción donde la mitad o más son exportados" (2015, p. 14). Ejemplo de ello es la megaminería a cielo abierto, algunos estudios han demostrado que los principales beneficiados de la explotación de las materias primas son los países del Norte Global; más bien, las corporaciones ubicadas en aquellos países (Grigera y Álvarez, 2013).

Otro caso de extractivismo es el de la arena, este recurso actualmente es codiciado por las empresas relacionadas con la construcción, ya que la acelerada expansión urbana ha elevado la demanda de esa materia prima. En una reciente investigación se enfatiza que, entre 1900 y 2010 el volumen global de recursos naturales utilizados en edificios e infraestructura de transporte se multiplicó por 23, entonces, la arena y la grava fueron los insumos de mayor porción colocándose entre los materiales más extraídos del mundo, superando los combustibles fósiles y la biomasa (Torres et al., 2017, p. 970).

En Indonesia la extracción masiva de arena es una constante, durante la década del 2000 se suscitó una situación extrema con la pérdida de territorio, hoy en día se estima que unas 25 islas han desaparecido, así como también las playas de otras ínsulas; la arena del fondo marino y de las playas, por su alta salinidad no es apta para su uso en la construcción, pero comúnmente su empleo es para rellenar las líneas de costas de los destinos turísticos debido a la incesante expansión urbana y el cambio climático (continuos huracanes, entre otros fenómenos), que son los causantes de la erosión de las costas, tal es el caso de las islas Canarias, uno de los principales destinos turísticos de España cuyo insumo es la arena del Sáhara, la cual se importa de ese desierto para atestar la playa de Las Teresitas, este supuesto lo reveló la Organización No Gubernamental (ONG) Western Sahara Resource Watch, quien ha monitoreado por años el material que sale del puerto de El Aaiún (Sáhara) hacia España, para la regeneración de playas y la construcción de edificios (Gómez-Cotta, 2018).

En este sentido, la frontera mercantil del turismo revela la presión extractiva de recursos primarios. El término commodity frontier (frontera mercantil) proviene del historiador ambiental Jason W. Moore (2003) para comprender la organización de los Cuatro Baratos, los cuales radican en el trabajo, la materia prima, los alimentos y la energía (Moore, 2015). Dichos elementos en el capitalismo temprano formaron parte del funcionamiento y revitalización de la acumulación del capital, por lo que la minería de la época de la colonia fortaleció la ley de valor a través de la apropiación y capitalización de los Cuatro Baratos (Moore, 2003). Actualmente el modo de producción está reproduciendo la ley de valor mediante nuevas fronteras mercantiles, en este aspecto, la industria del ocio es una actividad que de manera creativa está en el rol de la acumulación de ganancias.

Por lo tanto, la frontera mercantil del turismo se comprende como un modelo de producción que permite activar, reactivar o reconfigurar la acumulación, a saber, una expansión geográfica a través de la actividad turística para implantar modelos productivos que van desde los centros vacacionales de sol y playa, hasta con los emprendimientos con el turismo alternativo (ecoturismo, turismo de aventura, turismo rural, entre otros). Esta frontera -al igual que las demás- tiene sus formas particulares de apropiación y capitalización de los Cuatro Baratos, 
de manera que, este artículo se centra en uno de ellos: la materia prima. La apropiacióncapitalización de la arena como elemento barato se configura a partir de que el capitalismo es incapaz de producir la materia prima. Sin embargo, para obtener dicho elemento se adaptan nuevos mecanismos por medio de la frontera mercantil del turismo para enrolar un bien común hacia la ley de valor y, de esta forma garantizar la acumulación de capital.

En la isla Cozumel e Isla Mujeres la frontera mercantil del turismo se presentó como un organizador de la naturaleza, es decir, en estas islas el turismo fue introducido para dar un nuevo giro al modelo de acumulación con base en el enclave forestal (del chicle y la copra) de principios del siglo XX. En los años cincuenta del siglo pasado, el turismo en el Caribe mexicano se convirtió en un destino para el veraneo de estadounidenses (Santander y Ramos-Díaz, 2011); por lo que en Cozumel e Isla Mujeres la infraestructura especializada como hoteles, restaurantes y fondas empezaron a irrumpir para satisfacer las necesidades de los turistas (Palafox y Zizumbo, 2009). A partir de los años setenta con la apertura del polo turístico Cancún como Centro Integralmente Planeado (CIP), produjo una reconfiguración de la industria turística debido a lo cual las inversiones hacia la actividad comenzaron a provenir principalmente de capital extranjero (Escalera-Briceño y Ángeles-Villa, 2020). El CIP Cancún, rápidamente se colocó como destino turístico de relevancia a escala global, en consecuencia, la frontera mercantil del turismo se volvió más intenso en aquel lugar en cuanto a requerir de la apropiación y capitalización de materias primas, fuerza de trabajo, alimentos y energía para la acumulación de capital.

De lo anterior, es evidente que la zona norte de Quintana Roo existe una fuerte especialización a través del turismo (Escalera-Briceño y Ángeles-Villa, 2020); de modo que Cozumel, Isla Mujeres y el CIP Cancún son destinos turísticos significativos en aquella zona, además, en la actualidad presentan diversos conflictos ecológicos-distributivos o de justicia ambiental que derivan de la incesante acumulación de capital. En este estudio de caso mediante la frontera mercantil, tiene como objetivo de revelar los procesos de apropiación y capitalización de uno de los Cuatro Baratos (la materia prima [arena]) en el marco de la extracción de recursos naturales para la acumulación de capital. Las playas de la zona hotelera de Cancún se erosionaron por consecuencia de un huracán en el año 2005, para rehabilitar la línea costera, el gobierno mexicano facilitó la extracción de arena de los bancos ubicados en la isla Cozumel e Isla Mujeres para beneficiar a los capitalistas de la industria turística (principalmente hoteleros), puesto que, este hecho generó un conflicto socioambiental.

\section{Metodología}

Para lograr el objetivo del artículo, se profundizó en una revisión bibliográfica para discutir la operación del capitalismo, los autores referencia fueron Jason W. Moore, Eduardo Gudynas y Joan Martínez-Alier. De la propuesta de Moore (2017a, 2017b, 2016, 2015, 2013, 2003) se tomó la interpretación de los Cuatro Baratos y de su reorganización por medio de la frontera mercantil para beneficiar la acumulación del capital. De Gudynas $(2018,2015)$ la conceptualización del extractivismo que radica en el acaparamiento de recursos primarios, así como también de los altos volúmenes e intensidad de su extracción principalmente de los países del Sur Global. Cabe destacar que las aportaciones de ambos autores son de interés para señalar la operación del capital en el marco teórico. De igual manera, las contribuciones de MartínezAlier $(2011,2006)$ desde la ecología política a través de la justicia ambiental es de relevancia para este trabajo, aunque el turismo no se encuentra en su línea de investigación, la actividad está en constante crecimiento requiriendo cada vez más recursos naturales por lo que genera 
conflictos de tipo ecológico-distributivos. Debe precisarse que para reforzar el andamiaje teórico también se consultaron autores clásicos como Karl Marx, Rosa Luxemburg, Henri Lefebvre y contemporáneos tales como David Harvey, Neil Smith, James O'Connor, entre otros. Asimismo, se recurrió a bibliografía crítica del turismo, entre los que destacan: Ernest Cañada, Macià Blázquez, Joan Buades, Ivan Murray, Bram Büscher y Robert Fletcher.

El diseño metodológico implicó el empleo del método cualitativo a través de entrevistas semiestructuradas $(n=28)$. Se aplicó el instrumento a informantes clave que estaban al frente de dos organizaciones no gubernamentales que participaron en la oposición al proyecto de la extracción de arena, las activistas ambientales en el tiempo que se suscitó el conflicto ambiental estaban a cargo del Centro Mexicano de Derecho Ambiental (CEMDA) y de Cielo, Tierra y Mar (CITYMAR), éstas estuvieron desde el inicio cuando se presentó el proyecto hasta el paro de la obra. Igualmente, se entrevistaron a residentes locales que intervinieron en la consulta del proyecto de rehabilitación de playas en la zona hotelera de Cancún. El trabajo de campo se ejecutó en el año 2018 (diez años después del evento) entre los meses de mayo a septiembre, su propósito tuvo como objetivo obtener información sobre el problema propuesto (la extracción de arena), al mismo tiempo la aclaración de dudas, dado que la extracción del recurso natural se suscitó en sigilo y con la participación de funcionarios públicos y empresarios regionales cuyo entramado era difícil de entender por la diversidad de agentes que participaron. Además, como parte de la metodología, se realizó un análisis de contenido de las entrevistas las cuales fueron grabadas a través de equipo especializado, a su vez, transcritas y analizadas junto con fuentes de información secundaria. Posteriormente, se organizó la información (datos) para contrastarla con las categorías analíticas. En la parte que correspondió al análisis, en ésta se procedió a identificar los patrones comunes de las respuestas de las entrevistas, para simplificar este paso, se usó el programa de computo ATLAS.ti el cual permitió trabajar y organizar los datos mediante la asignación de códigos y categorías de análisis. Por último, las citas textuales se presentan en el artículo para relacionar la teoría con la realidad.

Adicionalmente, se recuperaron los documentos de la Manifestación de Impacto Ambiental (MIA) que elaboró el Banco Nacional de México y, el resolutivo con número de oficio S.G.P.A./ DGIRA/DG/3758/09 con fecha del 10 de julio de 2009 que emitió la Dirección General de Impacto y Riesgo Ambiental (DGIRA). El primer documento se utilizó en la investigación porque es un instrumento de la política ambiental del gobierno mexicano, cuyo objetivo principal es para prevenir, mitigar y restaurar los daños al ambiente, de igual forma, regular las obras o actividades para evitar los efectos negativos al ambiente, a saber, es un estudio técnico-científico que tiene como propósito indicar los efectos que puede ocasionar una obra o actividad sobre el medio ambiente, en este sentido, se utilizó el estudio para conocer los datos técnicos del proyecto de la extracción de arena. El segundo documento se empleó debido a que la autoridad ambiental mexicana emitió el resolutivo donde se decidió la extracción del recurso natural, dicho escrito es de importancia porque en él se detalla la consulta pública sobre la restauración de playas de la zona hotelera de Cancún en la cual participaron empresarios del sector turístico, consultores ambientales y sociedad en general. Si bien, al tratarse de un documento gubernamental, la información que expone es de valor para retomar el problema ambiental que se discutía en aquel tiempo. Por otra parte, se debe precisar que el proyecto de restauración de playas no trascendió en la academia, no obstante, distintos rotativos de alcance nacional y local-regional puntualizaron los hechos por lo que también se tomaron en cuenta para complementar desde distintos frentes el conflicto. Por lo tanto, esta información fue de importancia para el entramado sobre el conflicto ambiental. 


\section{Desarrollo}

3.1 La frontera mercantil del turismo, el extractivismo y la justicia ambiental: un marco teórico

El tema nodal es la frontera mercantil (commodity frontier) que trajo recientemente Jason W. Moore para entender el ascenso del capitalismo (Moore, 2015). Este proceso de extracción de recursos naturales ha ido cambiando con el tiempo; en la época de la colonia, punto de inflexión y de auge del modo de producción capitalista, la vasta materia prima que proporcionaba el Nuevo Mundo se basaba en la apropiación y capitalización de minerales como la plata, que ocurrió con gran intensidad en los Andes en Potosí y el llano mexicano en Zacatecas y Guanajuato (Moore, 2003; Galeano, 2004). Ante esto, Moore precisa que los movimientos de las fronteras mercantiles "no se debieron a una extensión de las relaciones de producción", más bien, estuvieron vinculadas con "la amplificación territorial y simbólicas para incorporar el trabajo no remunerado al servicio de la producción mercantil” (2016, p. 147).

Lo que se presenciaba en la época de la colonia era (aún lo es) una nueva ley de valor que se sustentaba a través de regímenes de "trabajo social abstracto y de naturaleza social abstracta", cuya reproducción radicaba bajo relaciones de apropiación y capitalización (Moore, 2017b, p. 223). Desde la economía política Marx lo denominó la acumulación originaria, si bien, el Nuevo Mundo significó el acaparamiento de tierra o suelo (medios de producción) para establecer relaciones sociales capitalistas (Marx, 1999).

Sin embargo, Moore (2015) entiende la transición al feudalismo - capitalismo al insertar un pensamiento complejo al controvertir que el capitalismo es una forma de organizar a la naturaleza; en este sentido, una expansión a todas direcciones que significa la supervivencia del modo de producción (así como también de saber cómo el ser humano coproduce la naturaleza), la cual es posible gracias a la apropiación de los Cuatro Baratos. De esta manera, las fronteras mercantiles se han reconfigurado y reorganizado desde los albores del largo siglo XVI a partir de la revolución minera y metalúrgica centrada en las mercancías de la Europa Central; los primeros signos de los nexos de la esclavitud moderna asociada al cultivo de la caña de azúcar en Madeira y luego en Santo Tomé; el implacable avance de las fronteras del comercio de pieles en Norte América; el incremento de la producción mexicana de plata en el siglo XVIII; el relativo agotamiento de los bosques ingleses y las reservas de turba holandesa como energía barata; la revolución agrícola inglesa; entere otros sucesos, facilitaron la apropiación y capitalización de los Cuatro Baratos (Moore, 2013, pp. 10-11).

Hoy, las fronteras mercantiles deben de renovarse y buscar esos elementos gratuitos porque los Cuatro Baratos ya no son vastos y está en riesgo la acumulación del capital, como dice Moore "debe buscar incesantemente y encontrar Naturalezas Baratas" (2015, p. 53). El capitalismo avanzado ha estado reformando la extracción de los Cuatro Baratos por medio de otras fronteras, por mencionar, la del petróleo (Malm, 2016); sin duda ésta ha hecho posible que las fuerzas productivas continúen en expansión e innovación (Moore, 2017). No obstante, el turismo como industria de la producción de lo exótico, por su génesis extractiva puede alojarse dentro de una frontera mercantil. Esta concepción es posible porque coproduce a la naturaleza a través del capitalismo y, viceversa (naturaleza en el capitalismo), es decir, la red de la vida (también tejido); lo antes dicho teóricamente parte de una forma de situar todo lo que hacen los humanos dentro de una totalidad mayor en la que la naturaleza humana es una poderosa especie de producción de medioambiente (Moore, 2014). Si bien, esta perspectiva dialéctica 
enfatiza que los humanos hacen al medioambiente y el medioambiente hace a los humanos (Moore, 2015).

La frontera mercantil del turismo es un gran extractor de los Cuatro Baratos, en esta se alojan claramente dos de ellos que descansan en el trabajo y las materias primas (tierra, playas, bosques, selvas.) de bajo costo o gratuitos respectivamente, por lo que esta nueva frontera mercantil las reorganiza para la mercantilización de la reproducción de la vida. Ante esto, el componente de trabajo barato la renueva con el propósito de establecer otras formas de explotación para la obtención de plusvalía. Los espacios turísticos al enrolarse en el crecimiento económico se convierten en imanes atrayendo a hombres y mujeres para ocupar los diversos puestos que ofrece la actividad, y generar un ejército industrial de desempleados, puesto que estas personas estarían dispuestas a entregar su fuerza de trabajo aceptando contratos con condiciones dolosas (Cañada, 2017; Rubí-González y Palafox-Muñoz, 2017). Lo que ocurre en los destinos es que se fomenta el servilismo por medio de la conversión de obreros y campesinos a la prestación de servicios (camareros, masajistas, guías, operadores, entre otros) para la reproducción de la acumulación del capital (Büscher y Fletcher, 2017).

Sobre la materia prima barata, Lefebvre (2013) proporciona pistas con la producción del espacio, igualmente Smith (2008) con la producción de la naturaleza, en ambas posturas, el énfasis es la imposición de un espacio para el productivismo, más bien, el espacio abstracto o del capitalismo (Lefebvre, 2013); de forma que, es una manera de interpretar como los seres humanos hacen medioambiente. Por lo tanto, en los destinos turísticos se presencia un fenómeno de acondicionamiento y equipamiento de espacios para la compra-venta de bienes y servicios con la particularidad de estar ubicados en lugares con belleza única (Bojórquez y Ángeles, 2019). En ese aspecto, la producción del espacio turístico constantemente necesita de bienes comunes para convertirlos en medios de producción, en este sentido, una playa como medio de vida para pescadores se transforma en un balneario o en una marina para el disfrute de quienes puedan pagar su uso.

Ahora bien, Gudynas (2018) ha empleado el concepto de extractivismo para enmarcar la explotación de los recursos naturales bajo un contexto histórico (por haber transitado como colonia) particularmente de América Latina. Esto último se relaciona con las fronteras mercantiles, ya que comparten características como la extracción de recursos primarios en grandes volúmenes y alta intensidad (oro, plata, diamantes, madera, petróleo, entre otros), además de que éstos son apropiados en su mayoría por empresas del Norte Global, por mencionar un ejemplo, las mineras canadienses que se implantan en México, de manera que ocasionan una dinámica negativa en los pueblos donde se asientan en el corto, mediano y largo plazo (contaminación del agua, destrucción de bosques y sobre todo despojos de tierras). Tal situación como en la época de la colonia permanece el saqueo de la periferia, así como el control de recursos naturales estratégicos por parte de capitales extranjeros (Delgado, 2014, p. 156).

Este carácter extractivista lo replica la frontera mercantil del turismo, no solamente en la apropiación de dos de los Cuatro Baratos (materias primas y trabajo), sino en algo más complejo que se vincula con la deuda de los países del Sur Global al depender de los préstamos de los Organismos Internacionales (OI), tales como el Banco Mundial (BM), el Banco Interamericano de Desarrollo (BID), entre otros, lo que facilita a las transnacionales turísticas anclarse en aquellos lugares (Lanfant, 1980; Palafox, 2013). 
Lo que entreteje la frontera mercantil del turismo es en primera instancia, con la apropiación, la demanda suministros prístinos de bienes comunes (tierra, playas, bosques, selvas, entre otros). Ello lo precisa el postulado de Luxemburgo (1978) con la reproducción ampliada del capital, la cual consiste en un proceso expansivo para incorporar nuevos territorios y recursos naturales no explotados para el sostenimiento vital del capital.

Las transferencias de recursos naturales es una particularidad del comercio en el modo de producción capitalista, éstas transforman las relaciones ecológicas entre el Norte y el Sur Global. Ejemplo de lo antes dicho es el trabajo de Clark y Foster (2012) con el negocio del guano/nitratos del siglo XIX, en el que expusieron que el recurso fue transferido desde Perú y Chile para enriquecer principalmente los suelos de Gran Bretaña y otros países imperiales con el propósito de beneficiar la agricultura, de manera que, los autores señalaron la violencia estructural con el que opera la economía-mundo para la acumulación del capital.

La fase de apropiación se complementa con la acumulación por desposesión de Harvey (2004), cuyo argumento es que el sistema capitalista por su constante desarrollo de las fuerzas productivas debe asegurar los medios de producción (o bienes comunes) y transformarlos en mercancía, a saber, una dinámica de despojo de los medios de subsistencia para la acumulación del capital (Grigera y Álvarez, 2013). Ante esto último, permite establecer que el turismo al igual que las demás actividades económicas su dinámica consiste en acaparar recursos primarios frescos para transformarlos en valor de cambio y, posteriormente, capitalizarlos a través de la experiencia turística (Büscher y Fletcher, 2017).

De esta manera se abre paso a una oleada de privatizaciones de bienes comunes a través del Estado (con sus políticas económicas) y las corporaciones capitalistas (locales, regionales, nacionales e internacionales) (Harvey, 2007). Para las economías del Sur Global representa un complejo proceso de subordinación de recursos naturales a la ley de valor, si bien la turistización es el establecimiento de transferencias ecológicamente desiguales por parte de empresas turísticas que bombean de los países periféricos sus recursos naturales en forma de dinero a través de la intensificación del suelo (ver Cañada y Blázquez, 2011).

La capitalización de estos dos factores (materias primas y trabajo) se ha logrado con tecnologías (desde la máquina de vapor hasta el uso de la energía fósil), así como también con la arquitectura financiera (Wall Street) (Keefer, 2011); aunque con esos agregados el capitalismo ha entrado en crisis, comúnmente escapa de sus problemas crónicos de sobreacumulación (Harvey, 2004). Sin embargo, el cambio en el metabolismo (el desarrollo del capitalismo en la naturaleza y sobre sus salidas a las crisis), el modo de producción encamina a formas eficientes de reorganización de los Cuatro Baratos para continuar con la acumulación del capital (Moore, 2017a). De ello, Moore (2013) especifica que los Cuatro Baratos son puestos a trabajar por el capital intensivo mediante las innovaciones para el incremento de la productividad. Por consiguiente, el turismo como industria es una actividad más dentro del proyecto moderno civilizatorio el cual consiste en estimular la acumulación del capital.

De lo antes mencionado se relaciona con la expansión geográfica que pone de relieve Harvey (1998) con la construcción social del espacio y tiempo. El geógrafo inglés toma de Marx la aniquilación del espacio-tiempo, el cual consiste que las innovaciones dadas en el proyecto moderno civilizatorio sirven para superar los beneficios económicos, a saber, una aceleración de la rotación del capital. Bajo este precedente el turismo se concibe como una forma particular de relación social para dinamizar el espacio-tiempo. La industria del ocio después de la Segunda 
Guerra Mundial se convirtió en una innovación para otorgarle una nueva forma de valor al suelo (espacio), las playas y, en general al paisaje, ya que éstos pasaron a transformarse en mercancías para su consumo (de una manera más intensiva). Ejemplo de ello el Mediterráneo español convertida en una gran piscina de veraneo en la época de la posguerra (Buades, 2011). En el capitalismo avanzado el turismo todavía continúa reemplazando actividades que no estimulan la acumulación del capital, hoy en día con estrategias de inversión con el capital financiero cuyo entramado es la especulación inmobiliaria.

Además, el turismo no solamente coloca la acumulación del capital a la altura de la actual economía-mundo (en una etapa neoliberal), sino que al mismo tiempo sostiene y le da vida al capital de diversas formas. Ante esto, Moore $(2003,2015)$ asevera que a través de los Cuatro Baratos, los cuales por medio de las fronteras mercantiles se encarga de buscarlos y organizarlos. Desde esta perspectiva es que el turismo se presenta como una frontera mercantil en la búsqueda constante de recursos (los Cuatro Baratos) principalmente de los países del Sur Global. De manera que, la frontera mercantil del turismo constituye una fuerza globalizadora como estrategia de apertura del mercado para que el capital siga orbitando en la infinita acumulación de beneficios económicos.

Por otra parte, el cercamiento de recursos naturales se tiñe de violencia estructural como la depredación, el despojo y el fraude, por lo que cusa conflictos sociales, como señalan InfanteAmate, González de Molina y Toledo debido "al acceso y aprovechamiento de los recursos naturales tanto a escala local como global” (2017, p. 141). En este sentido, Martínez-Alier (2006) ha desarrollado el concepto de conflictos ecológico-distributivos o de justicia ambiental, quien argumenta que no todos los seres humanos son igualmente afectados por la mercantilización de la naturaleza, además, enfatiza que unos acaparan más recursos que otros y, que algunos con mayores costos que otros. Por lo tanto, estos problemas conducen a movimientos sociales motivados por el proceso de expansión y explotación de la fuerza de trabajo, así como de la naturaleza (O'Connor, 2001). De ello se desprenden (entre otros) inconformidades por la degradación del medio ambiente, ante la luz de la justicia ambiental los pobres y demás desposeídos son limitados al irrumpir reglamentaciones y prohibiciones para transformaraprovechar los recursos naturales (Martínez-Alier, 2011). Tal situación es contraria para los capitalistas, ya que éstos se privilegian de las desregulaciones ambientales y adecuaciones estructurales que posibilitan la maximización de beneficios económicos.

3.2 La frontera mercantil del turismo y la apropiación-capitalización de la arena en la Isla Cozumel e Isla Mujeres: un preámbulo

En este artículo se refuerza la idea de que las corporaciones capitalistas continúan con la acumulación del capital por medio de la apropiación-capitalización de la arena (materia prima). Sin duda, lo sucedido en la isla Cozumel e Isla Mujeres con la extracción de arena da cuenta de ello, se subraya que la frontera mercantil del turismo como planteamiento para entender la reorganización hasta ahora de uno de los Cuatro Baratos, en este sentido, se expone el de la arena como un recurso necesario para reproducir la actividad turística y en consecuencia la acumulación de capital.

Los bancos de arena afectados se ubican dentro del Mar Territorial de México, debe precisarse que sus formaciones se deben a fenómenos naturales como las depresiones tropicales y ciclones, el Banco Punta Norte se encuentra en la parte norte de la isla Cozumel (ver figura 1); las profundidades de este banco oscilan de los -12 a los -29 metros. 
Figura 1: Ubicación del banco de arena Banco Punta Norte.
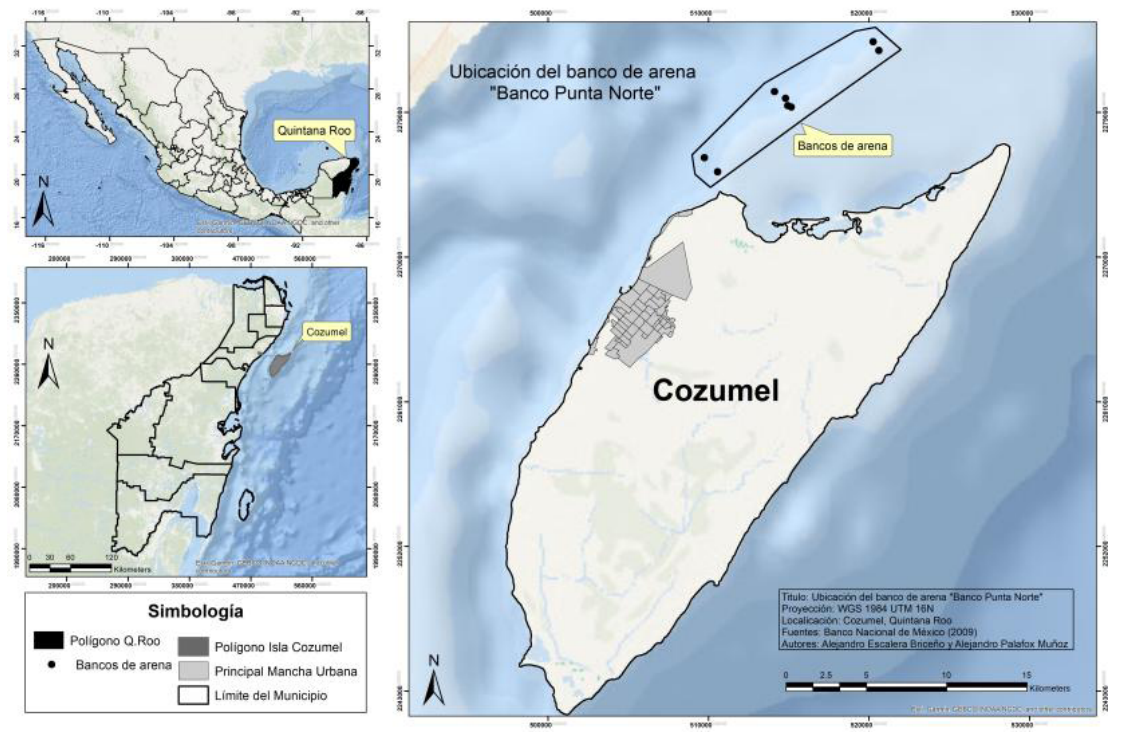

Fuente: Banco Nacional de México, 2009.

Por otra parte, el banco la Ollita II (ver figura 2) cuenta con una profundidad promedio entre los 22 y 30 metros con una superficie de 1,200 hectáreas, el diámetro de la arena está en un promedio de 0.36 milímetros (Banco Nacional de México, 2009, p. 18).

Figura 2: Ubicación del banco de arena la Ollita II.
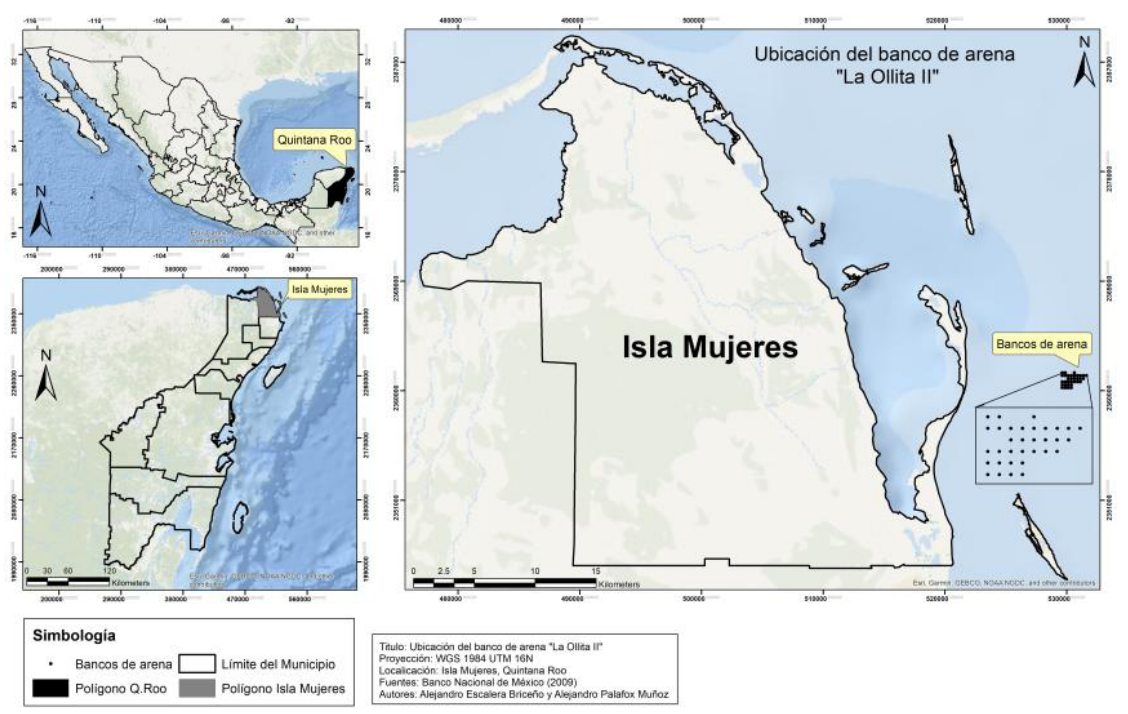

Fuente: Banco Nacional de México, 2009.

La erosión de las playas que ocasionó el paso del huracán Wilma en el año 2005 en el Caribe mexicano, afectó a la industria del turismo. El Fondo Nacional de Fomento al Turismo (FONATUR) estimó que la región dejó de percibir unos 15 millones de dólares diarios por concepto de ocio (Banco Nacional de México, 2009, p. 4). En este mismo tenor, el ciclón causó daños a la infraestructura hotelera, comercial, vial, portuaria y aeroportuaria las cuales derivaron en 7.8 billones de dólares en pérdidas en los destinos de la zona norte de Quintana Roo (Cozumel, Playa del Carmen, Cancún, Isla Mujeres) (Palafox y Dzul, 2014, p. 169). 
Un año después, el gobierno federal invirtió 235 millones de pesos para la recuperación de 11.5 kilómetros de playas de la zona hotelera de Cancún, sin embargo, aquella acción no sirvió para mantener en condiciones adecuadas las costas mexicanas, puesto que continuaron azotando las tormentas y depresiones tropicales (Banco Nacional de México, 2009, p. 4). No obstante, en el año 2009 el Estado promovió a través del Banco Nacional de México, S.A., el proyecto "Restauración, recuperación, sostenimiento y mantenimiento de la zona federal marítimo terrestre de Cancún, Playa del Carmen y Cozumel”. En la Manifestación de Impacto Ambiental (MIA), colaboró la Comisión Federal de Electricidad (CFE) con las investigaciones de campo, se impulsó la reposición de las playas para la zona hotelera de Cancún, Playa del Carmen y Cozumel para el embellecimiento del paisaje costero.

El proceso de valorización de la arena se constata mediante la Manifestación de Impacto Ambiental (MIA). Este documento precisa a la isla Cozumel con el Banco Punta Norte (el de mayores depósitos de arena) y otro en Isla Mujeres con el banco la Ollita II, con un volumen estimado entre los 2.5 y los 2.8 millones de metros cúbicos (Banco Nacional de México, 2009, p. 71). Ahora bien, el Banco Punta Norte se localizó a 17 kilómetros frente a la costa norte de la isla Cozumel, el estudio de viabilidad apreció una superficie de alrededor de 17 kilómetros cuadrados. En comparación con el banco la Ollita II, el de Cozumel se evaluó con un volumen de 40 millones de metros cúbicos de arena, por lo que se colocó como el más abundante (Banco Nacional de México, 2009, p. 73). En la MIA se establecieron los volúmenes de extracción de los dos bancos, los cuales se estimaron conforme a los perfiles barométricos, estudios que se llevaron a cabo por medio de equipo geofísico y a la apreciación de las tasas de retorno a través de calas de contacto y observación directa con las estaciones de buceo.

El Banco Nacional de México determinó que el volumen de extracción para el banco la Ollita II consistiría en 1.5 millones de metros cúbicos para enviar a las playas de la zona hotelera de Cancún, complementándose con 4.1 millones de metros cúbicos provenientes del banco Punta Norte; de ese mismo banco se utilizarían 800 mil metros cúbicos para rellenar las costas de Playa del Carmen y 130 mil metros cúbicos para sanear las playas de Cozumel (2009, p. 76). Así mismo, se estipuló el relleno de una franja de 11 kilómetros, tramo que comprendía entre Punta Cancún y Punta Nizuc, hoy por hoy la zona hotelera del destino turístico de Cancún (Banco Nacional de México, 2009, p. 38). Para Playa del Carmen, el proyecto de rehabilitación se programó en dos etapas, la primera, para mejorar 4.2 kilómetros entre Playacar a la Playa Xcalacoco y, la segunda etapa, el tendido de la playa de aproximadamente 30 y 40 metros de ancho a partir de la infraestructura hotelera en el lugar antes señalado (Banco Nacional de México, 2009, p. 5).

\subsection{La fiebre de la arena: la apropiación del Banco Punta Norte en la isla Cozumel y la Ollita II en Isla Mujeres}

El hilo conductor en esta fase de apropiación de arena lo constituye el entramado de la acumulación por desposesión como parte de un proceso de acaparamiento de recursos naturales (materia prima desde los Cuatro Baratos). En los últimos años, en el Caribe mexicano existe una presión por acaparar recursos naturales para convertirlos en espacios exclusivamente para el capital (Escalera-Briceño et al., 2018); ejemplo de ello es el Centro Integralmente Planeado Cancún, una producción del espacio para transformar el suelo en una mercancía, un nuevo ambiente (en Smith una segunda naturaleza) para que la disfruten (la mercancía) los turistas y, a la vez, en un medio de producción, en la cual sus playas, manglares, selvas, lagunas se conviertan en insumos para el desarrollo turístico (hotelero-inmobiliario, entre otros). 
Esta dinámica de privatización de bienes comunes (una tendencia global) es una manera de colocarlas a disposición del mercado. Ante esto, es lo que Moore (2015) precisa con los Cuatro Baratos, componentes que sirven como una fuente clave para revitalizar la acumulación del capital. La arena como materia prima (componente de los Cuatro Baratos) es un recurso natural que debe ser sometida a la ley de valor, es decir, a la comercialización. De ello, la informante clave puntualizó lo siguiente:

\begin{abstract}
Nos informamos por planos donde hay arena y sabemos perfectamente, por ejemplo, en Punta Maroma...si se cruza de aquí (Cozumel) a Cancún en avión se puede ver claramente unos arenales enormes dentro del mar. [...] Cozumel tiene arena en el banco norte y porque se tenía un estudio previo por parte de la Comisión Federal de Electricidad para el cable de la energía eléctrica, se tomó como punto para el proyecto de recuperación de playas. (G. Álvarez, 5 de septiembre de 2018)
\end{abstract}

El proceso de despojo inicialmente se suscitó a través de un estudio previo, por lo que la apropiación de arena de esa manera comenzó a formar parte de la ley de valor. Si bien, Moore proporciona pistas para entender lo antes expuesto: “la búsqueda continuada, rápidamente expansiva e incansablemente innovadora para convertir los Cuatro Baratos (en este caso la materia prima con la arena) en oportunidades de inversión" (2015, p.14). Por lo tanto, la fiebre de la arena representó una coyuntura para establecer beneficios económicos, como lo menciona la informante clave:

\begin{abstract}
Sabemos como están establecidas esas obras (relleno de playas) y, como van las corrientes es lo que está generando la erosión (playas de la zona hotelera) sobre todo si se están metiendo (invirtiendo) dinero de la federación, pues no tendría que ser la federación nomás dando dinero y una parte de los desarrolladores sin que estén dispuestos a hacer un plan más integral. [...] no veo proyecciones en cuanto a cambio climático o temas de cambio de corriente, de elevación del nivel del mar...y entones es entrar a la visión cortita, nomás para llevar, traer y rellenar (en relación con la arena). (A. Serrano, 12 de mayo de 2018)
\end{abstract}

El proyecto de recuperación de playas no fue para generar un beneficio amplio, más bien, un apoyo inmediato a los capitalistas para restaurar la acumulación del capital. Entonces, el Estado se encargó de la restauración de las costas afectadas de la zona hotelera de Cancún. Así mismo, después del huracán Wilma el Ejecutivo Federal se reunió con 200 empresarios (hoteleros) para refrendar su compromiso proporcionándoles una ayuda de aproximadamente de 200 millones de pesos para solventar los gastos del dragado de arena (Muñoz, Gómez y Mariscal, 2012).

El gobierno federal tenía un compromiso con los hoteleros de Cancún y le valió con lo que le pasara a Cozumel, yo nunca estuve de acuerdo con eso porque digamos que Cozumel es el hermano mayor (como construcción social como pueblo) y se debería respetar. (G. Álvarez, 5 de septiembre de 2018)

Debe precisarse que hubo un primer proyecto de restauración de playas, pero fue afectada por las malas condiciones del clima puesto que las costas de la zona hotelera de Cancún volvieron a erosionarse. Por supuesto, esta primera etapa bajo el argumento de satisfacer la experiencia turística (hoteles con playas blancas con fina arena). 
Desde mi punto de vista, un solo relleno, sin que vaya de la mano con un análisis (se refiere a un análisis más amplio que contemple lo ambiental y social y no solamente lo económico) que esa también se dijo en 2008/2009, pues analicemos las obras que están generando mayor erosión para que tal vez modifiquen una parte, a lo mejor de ahí ciertos cambios que se deben de hacer en obras o en estructuras que ya están en las zonas de desarrollo porque es un tiradero de dinero (derroche). Si sabemos como están establecidas esas obras y como van las corrientes es lo que está generando la erosión ihay que cambiar algo! (A. Serrano, 12 de mayo de 2018)

En respuesta, el Estado impulsó una segunda etapa de restauración, por lo que elaboró un plan de reconstrucción con mayor planificación. No obstante, la MIA enfatizó la situación de las costas y sobre todo la justificación ambiental, aunque el documento no subrayó que el recurso natural principalmente serviría para el beneficio económico de unos cuantos (los empresarios). En general, la apropiación de arena de los dos bancos (Banco Norte en Cozumel y La Ollita II en Isla Mujeres) representaron una oportunidad de inversión temporal a una problemática mayor. Sin embargo, la solución ante lo económico (nomás para los capitalistas) fue la apropiación de arena (materia prima) de un lugar distante. Debe precisarse que la apropiación de recursos natrales o bienes comunes no necesariamente se suscitan dentro de la esfera global (como el caso del guano en Perú del siglo XIX), sino también son visibles al interior de una escala regional-local como el que se trata de poner de relieve en esta investigación.

\subsection{La capitalización de los bancos de arena: un beneficio para los empresarios}

Como se ha dicho en párrafos anteriores, la actividad turística necesita de recursos naturales para la reproducción y la expansión del sistema capitalista mundial (Fletcher, 2016). En el estudio de caso con la extracción de arena en el Caribe mexicano, el turismo en la zona norte de Quintana Roo como innovación comenzó precisamente a la par de la creación de "paraísos turísticos" en la etapa final del Estado benefactor con el Centro Integralmente Planeado Cancún en 1970 (el primero de su tipo en México). La capitalización representó una época dorada para la actividad turística y, sobre todo, para los capitalistas, provenientes principalmente de las cadenas hoteleras españolas que, en la actualidad continúan operando en aquella zona bajo una nueva forma de colonización de tierras (Buades, 2014). Sin embargo, este esquema de capitalización del turismo es una manera generalizada de como se desarrolla en el Caribe mexicano. Ahora bien, la capitalización tiene varios trazos que dificulta su contextualización.

La extracción de arena en el Caribe mexicano consistió en un proceso de convertir la materia prima en un beneficio futuro. No obstante, debe precisarse que los capitalistas no compraron la arena, más bien, se trató de la obtención de un recurso a través de un bien común que no produjo el capital (se remite a la renta de Marx, el cual consiste a grandes rasgos en una valorización de un bien natural escaso, es decir, sometido a la ley de valor). La erosión de las costas ocasionado por los fenómenos naturales en la zona hotelera de Cancún supuso que afectaría a la experiencia turística por lo que impactaría de manera negativa a la acumulación de ganancias. En virtud de ello, comenzó una valorización de la arena para incorporarla a un proceso de producción capitalista, es decir, acapararla para transformarla en una mercancía, proceso que se detalla en párrafos de arriba en la fase de apropiación en la cual se relaciona con la acumulación por desposesión.

De esta manera, la arena como recurso natural escaso empezó a tener un valor para la reproducción de la actividad turística. Cabe señalar que la arena es una materia prima elemental para atraer a los turistas y que ésta abundaba en la zona hotelera; sin embargo, al desaparecer 
de la costa dio inicio la valorización de la arena de otros lugares para atestar la franja costera turística (a través de la MIA que elaboró el Banco Nacional de México). Evidentemente el capital incapacitado ante la producción de arena (hoteleros y demás inversionistas que no fabrican el recurso natural), los capitalistas tuvieron que recurrir al gobierno federal para que los abasteciera del recurso natural, de modo que contaba con los reservorios de arena de alta calidad ubicados a kilómetros de distancia (la transferencia de la arena de un espacio menos desarrollado pero con importante valor biológico a otro más dinámico para las actividades turísticas).

Figura 4: Los bancos de arena en el Caribe mexicano.

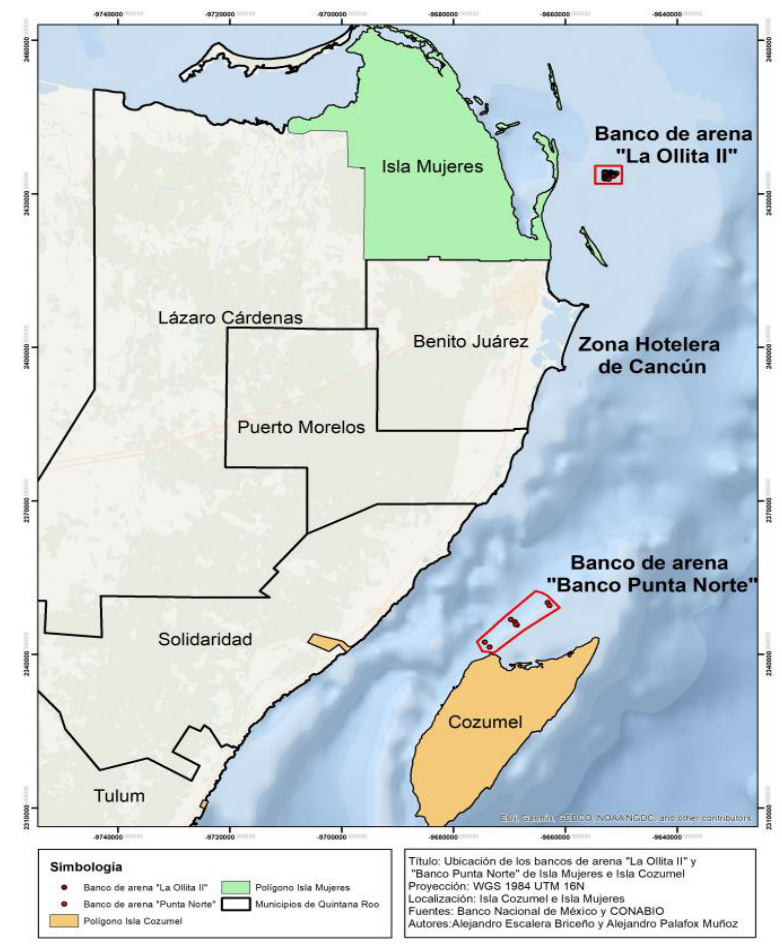

Fuente: Banco Nacional de México, 2009.

Para la extracción de arena (Banco Punta Norte y la Ollita II) (ver figura 4) se visualizaron dos características: a) la gran extensión de arena blanca; y b) granos finos de aproximadamente 0.23 milímetros; elementos necesarios para la restauración de las costas (Banco Nacional de México, 2009, p. 19). Los favorecidos de la recuperación de playas fueron los hoteleros, ese supuesto se confirma ya que en la MIA no exigía aportación monetaria. Este beneficio hacia los capitalistas se suscitó porque el grueso de la extracción de arena se destinaba a los hoteles enclavados en la zona hotelera de Cancún. Bajo ese contexto, en la MIA se estipuló que el Estado invertiría en Cancún alrededor de 650 millones de pesos, para Playa del Carmen unos 90 millones de pesos (Banco Nacional de México, 2009, pp. 11-12).

La arena valorizada de la Ollita II sirvió para beneficiar a nueve hoteles, una plaza comercial y dos torres de condominios, todos ubicados en la zona hotelera de Cancún; asimismo, un rotativo local reveló los nombres de los empresarios favorecidos, entre ellos el Grupo Sunset; y los hoteles Gran Caribe Real y The Royal (Caballero, 2009b). En una nota de la Jornada de mediados de diciembre de 2009, precisó que hasta esa fecha se habían reparado tres kilómetros de playas de la zona hotelera de Cancún (de la Ollita II), en esa misma publicación se constataba que en febrero de 2010 concluiría la restauración de playas en Cancún (los 11 kilómetros de playas) 
gracias al complemento de arena del Banco Punta Norte (ocho kilómetros) (Martoccia, 2009); en este sentido se correlaciona con la extracción de arena que se llevó a cabo desde finales de noviembre de 2009 hasta marzo de 2010 en el Banco Punta Norte para succionar los 4.1 millones de metros cúbicos autorizados por la MIA.

\subsection{El conflicto ecológico-distributivo generado por la extracción de arena}

El modelo de desarrollo turístico en la zona norte de Quintana Roo a partir del Centro Integralmente Planeado Cancún se basa en el uso intensivo de los recursos naturales. Bajo este precedente, los megaproyectos en el Caribe mexicano están vinculados con la mercantilización de la naturaleza, lo que genera un descontento social por el aumento de la violencia al medioambiente (pérdida de arrecifes coralinos, selvas, manglares, entre otros). Este crecimiento acelerado de la industria del ocio ha ocasionado que la sociedad se organice para defender los bienes comunes. Por mencionar, en los años noventa irrumpió un movimiento ambiental por la destrucción del arrecife de coral debido a la construcción y operación de una terminal portuaria para el atraco de cruceros en la isla Cozumel, en la cual aglutinó asociaciones civiles como el Comité para la Protección de los Recursos Naturales, el Grupo de los 100 Internacional y el Centro Mexicano de Derecho Ambiental, organizaciones que señalaron los incumplimientos en los reglamentos ambientales (Martínez, 2010).

La importación de arena de la isla Cozumel hacia la zona hotelera de Cancún creó un conflicto socioambiental. Cabe mencionar que, desde el anuncio de la explotación de arena, la organización no gubernamental Cielo, Tierra y Mar (CITYMAR) interpuso una queja para frenar el proyecto de restauración de playas porque violentaba la biodiversidad marina, argumentando que el banco Punta Norte es un área de anidación del caracol rosado (especie protegida) y, que las consecuencias de los trabajos de dragado dañarían el hábitat de aquella especie (Martoccia, 2010). Además, debe precisarse que, en la MIA, se constituía como un proyecto de extracción de arena con una vigencia de 10 años con el propósito de abastecer el recurso primario cada vez que fuera necesaria en los centros vacacionales (Banco Nacional de México, 2009).

Este hecho, desde la ecología política proyecta el término de ecología de los pobres (MartínezAlier, 2011), cuya influencia en Cozumel se suscitó al establecerse una resistencia local y regional que se unió a los reclamos de los conflictos socioambientales en todo el globo, principalmente del extractivismo de recursos primarios. En ese tiempo, la MIA no podía ser aprobada sin una consulta pública, por lo que la población local, al saber del conflicto y la demanda interpuesta acudieron al evento el 27 de mayo de 2009 en el Centro de Convenciones de Cozumel, donde se presentaron 29 ponencias las cuales en su mayoría estuvieron en contra del dragado de arena. Las exposiciones a favor del proyecto correspondían a las empresas BestDay, Sunset, entre otros. En resumen, la extracción de arena radicaba en la racionalidad económica cuyo beneficio se centraba para el sector hotelero de Cancún.

En la consulta pública se valoraron los argumentos técnicos y científicos para la toma de una decisión, por lo que los saberes de los isleños no fueron de sustento técnico ambiental. Ahora, los comentarios validos de ese ejercicio los efectuó la Fundación Plan Estratégico de Cozumel, A. C. En tanto, las observaciones que se presentaron un día después fueron de rechazo contundente y oposición objetiva al proyecto. Sin embargo, a pesar del señalamiento desfavorable y de una serie de recomendaciones para proteger los recursos naturales de la isla Cozumel, la explotación de materiales en el fondo marino del Banco Punta Norte se realizó. La obra de dragado inició el 
31 de octubre de 2009 inaugurada por el Secretario de Turismo y el gobernador del estado de Quintana Roo en una ceremonia en sigilo (Caballero, 2009b).

Pese a todo el ambiente desfavorable CITYMAR a través del Tribunal Federal de Justicia y Fiscal y Administrativa (TFJFA), este último le otorgó la suspensión definitiva contra la extracción de arena del Banco Punta Norte, ante esa resolución el tribunal fijó una fianza de 15 millones de pesos en un plazo de 72 horas para entregar el dinero y con eso confirmar la interrupción de la obra. No obstante, la organización ambientalista CITYMAR inició una recolecta para obtener en tres días el monto fijado. En entrevista con Guadalupe Álvarez, comentó que su esfuerzo no fue suficiente para reunir el dinero. Hoy, el proyecto se encuentra suspendido, pero desde una perspectiva jurídica puede ser impugnada mediante la interposición del recurso de reclamación ante un tribunal (Caballero, 2009a).

La suspensión del dragado de arena causó inconformidad en la parte empresarial. El grupo hotelero Palace -actualmente con más de seis mil cuartos de hotel- manifestó que la obra no dañaba al medioambiente y, confiaba que los ambientalistas recapacitarían ya que la MIA se encontraba autorizada, resaltó que la preocupación de la población local era por el caracol rosado, a pesar de que los habitantes no respetaban la temporada de veda del molusco (Caballero, 2009b). La molestia de los ambientalistas y de la gente local radicaba de que el proyecto era un arreglo temporal, más aún, los isleños en la consulta pública enfatizaron que los responsables eran los que otorgaban permisos de construcción en las dunas de arena a los consorcios hoteleros, siendo el capital el origen en la erosión de costas.

Este conflicto ecológico-distributivo no es un caso aislado en la región, años más tarde, irrumpiría el caso de Tajamar, en Cancún. La frontera mercantil del turismo necesita de la apropiación y capitalización de los recursos primarios para la realización de la experiencia del turista; sin embargo, las resistencias de los ambientalistas aún no abstraen el problema, en contraste con los saberes locales que reconocen las causas del fenómeno. La extracción de arena da cuenta de ello, la población local tuvo presente que era el capital y su acelerada expansión en la zona hotelera de Cancún el causante de la erosión y no los huracanes que azotan a los destinos turísticos de Quintana Roo. Sin duda este ecologismo brilla dentro de los conflictos socioambientales para opacar los de la ecología profunda que en especial atención es pensada desde la clase empresarial con el desarrollo sustentable (playas limpias, ecoetiquetas, prohibición de plásticos, protección de especies, entre otros), el cual es una continuación del crecimiento económico.

\section{Conclusiones}

La frontera mercantil del turismo es una manera de entender las bases de la economía-mundo, sobre todo las fases de acumulación o, más bien, la reorganización hasta ahora de dos de los Cuatro Baratos bajo esta perspectiva de modelo productivo turístico. Esta frontera de producción, de igual forma sirve para entender que la obtención de elementos baratos no es exclusiva de una economía global (centro-periferia), sino también se reproducen en los ámbitos nacional, regional y local. Este estudio de caso no excluye la escala planetaria, más bien, refuerza que la realidad local está interconectada con las diferentes escalas (multiescalar). Por supuesto, la actividad turística es compleja al no poner en evidencia a un agente o agentes como es patente en los múltiples conflictos que causa la minería. En algunos estudios de turismo (el denominado turismo de lujo), el extractivismo parte de la apropiación de bienes comunes cuya importancia son los procesos de mercantilización y las dinámicas de acumulación por desposesión. 
En cuanto a los conflictos socioambientales, el capitalismo avanzando está creando su propio ecosistema poniendo en peligro su reproducción, al no encontrar la organización de la naturaleza o de los Cuatro Baratos y, por el otro, un modo de producción opresivo con el propósito de asegurar los bienes comunes. Esta dinámica puede ser comprendida desde una perspectiva de la economía-mundo, es decir, no solamente como un momento del capital en su manifestación neoliberal (cambio sistémico), más bien, a partir de sus fases de acumulación (desde el capitalismo temprano).

Cada uno de los conflictos históricos hasta los actuales están interconectados, así como también las crisis de acumulación del capital. Para ampliar lo antes dicho, debe verse el capitalismo en la naturaleza como una forma de romper con el dualismo capitalismo y naturaleza. De ello, se desarrolla una crítica al sistema-mundo para nombrarla ecología-mundo, lo que permite entender que el capital se encuentra creando su propio ambiente, como resultado, las múltiples crisis: la alimentaria, de desigualdad, pobreza, de desaparición de especies, la violencia, entre otras. Sin embargo, el ambiente se adapta al sistema haciendo que las lluvias ácidas, la contaminación de los mares y del aire, así como el cambio climático, la aparición de nuevas enfermedades, entre otros, irrumpan como parte de la red de la vida. Lo antes dicho se torna complejo en la era geológica del capitaloceno ya que pone en evidencia que los capitalistas son los responsables de la crisis civilizatoria y no todos los seres humanos como lo argumenta la era del antropoceno.

Ahora bien, un conflicto socioecológico contemporáneo en el Caribe mexicano relacionado con la extracción de la arena, es una síntesis de los efectos del capitalismo, a saber, se acopla como un gajo ante el histórico desarrollo de las fuerzas productivas desde el siglo XVI. También, el trabajo se une a la ecología política para demostrar que la industria del turismo no es un guardián ecológico, sino una frontera mercantil para organizar (con violencia) a la naturaleza y revitalizar la acumulación del capital, además, de que esta disciplina híbrida revela la complejidad de intereses, estructuras de poder, contrafuerzas, conflictos y propuestas alternativas. Hoy por hoy la zona norte de Quintana Roo es un bastión para la acumulación del capital por lo que se suscita violencia estructural como lo expuesto con la extracción de arena, aunque existe movilización por el medio ambiente sigue imperando el discurso del desarrollo como generador de bienestar en la sociedad; sin embargo, es todo lo contrario ya que los beneficiados de la producción del espacio son los capitalistas.

\section{REFERENCIAS}

Banco Nacional de México (2009). Manifestación de impacto ambiental, restauración, recuperación, sostenimiento y mantenimiento de la zona federal marítimo terrestre de Cancún, Playa del Carmen y Cozumel. http://dof.gob.mx/nota_detalle.php?codigo=5087409\&fecha=16/04/2009

Bojórquez, J., y Ángeles, M. (2019). Turismo y polarización social en Los Cabos, México. El proyecto Zona Dorada. Bitácora Urbano Territorial, 29(2), 117-126. https://doi.org/10.15446/bitacora.v29n2.77609

Buades, J. (2014). Exportando paraísos. La colonización turística del planeta. Alba Sud Editorial.

Buades, J. (2011). Geopolítica, neoliberalismo y turismo en los Países Catalanes. Alba Sud, (10), 2-18. http://www.albasud.org/publ/docs/40.pdf

Büscher, B., \& Fletcher, R. (2017). Destrutive creation: capital accumulation and the structural violence of tourism. Journal of Susteinable Tourism, 25(5), 651-667. https://doi.org/10.1080/09669582.2016.115 9214 
Blázquez, M., Buades, J., Cañada, E., y Murray, I. (2011). La balearització global: conflictes socioambientals de la construcción d'hotels balears a El Carib i América Central'. Quaderns de Pau i Solidaritat, (43), 1-51. http://www.albasud.org/publ/docs/45.ca.pdf

Caballero, S. (2009a, 28 de octubre). Paran en Cozumel extracción de arena. INFORURAL. https://www. inforural.com.mx/paran-en-cozumel-extraccion-de-arena/

Caballero, S. (2009b, 4 de noviembre). Confían hoteleros en extraer arena de banco de Cozumel. NOTICARIBE. https://cutt.ly/aQFsPm4

Cañada, E. (2017). Un turismo sostenido por la precariedad laboral. Papeles de Relaciones Ecosociales y Cambio Global, (140), 65-73.

Cañada, E. y Blázquez, M. (eds.) (2011). Turismo Placebo. Nueva colonización turística: del Mediterráneo a Mesoamérica y El Caribe. Lógicas espaciales del capital turístico. EDISA.

Clark, B., y Foster, J. (2012). Imperialismo ecológico y la fractura metabólica global. Theomai, (26), https:// cutt.ly/NQFsLOV

Delgado, G. (2014). Metabolismo social y el bien común de la humanidad: ecología economía y política. En G. Delgado (Coord.). Buena vida, Buen vivir: imaginarios alternativos para el bien común de la humanidad (pp. 145-184). UNAM, Centro de Investigaciones Interdisciplinarias en Ciencias y Humanidades.

Escalera-Briceño, A., y Ángeles-Villa, M. (2020). La Estructura Social de Acumulación en el Caribe mexicano. El caso de la zona norte de Quintana Roo. Aposta. Revista de Ciencias Sociales, (87), 86105. http://www.apostadigital.com/revistav3/hemeroteca/aescalera.pdf

Escalera-Briceño, A., Palafox-Muñoz, A. y Ángeles-Villa, M. (2018). La producción del espacio turístico en la era del capitaloceno. Biblio 3W. Revista Bibliográfica de Geografía y Ciencias Sociales, 23(1.254), 1-22. https://doi.org/10.1344/b3w.0.2018.26827

Fletcher, R. (2016). Tours caníbales puesto al día: la ecología política del turismo. Ecología Política, (52), 26-34.

Galeano, E. (2004). Las venas abiertas de América Latina. Siglo Veintiuno Editores.

Gómez-Cotta, C. (2018, 24 de mayo). El devastador negocio del tráfico de arena. EL PAís. https:/elpais. com/elpais/2018/05/14/eps/1526299463_273121.html

Gudynas, E. (2018). Extractivismos: el concepto, sus expresiones y sus múltiples violencias. Papeles de Relaciones Ecosociales y Cambio Global, (143), 61-70.

Gudynas, E. (2015). Extractivismos en América del Sur y sus efectos derrame. Boletín, (76), 13-23.

Grigera, J. y Álvarez, L. (2013). Extractivismo y acumulación por desposesión. Un análisis de las explicaciones sobre agronegocios, megaminería y territorio en la Argentina de la posconvertibilidad. Theomai, (27-28), 80-97.

Harvey, D. (2007). El nuevo imperialismo. Akal.

Harvey, D. (2004). El “nuevo" imperialismo: acumulación por desposesión. Socialist Register, (40) 100129. https://socialistregister.com/index.php/srv/article/view/14997/11983

Harvey, D. (1998). La condición de la posmodernidad. Investigación sobre los orígenes del cambio cultural. Amorrortu editores.

Infante-Amate, J., González De Molina, M. y Toledo, V. (2017). El metabolismo social. Historia, métodos y principales aportaciones. Revista Iberoamericana de Economía Ecológica, 27, 130-152. https://raco. cat/index.php/Revibec/article/view/335101

Keefer, T. (2011). Wall Street is a way of organizing nature: an interview with Jason Moore. Upping the Anti a Journal of Theory and Action, (12), 41-53. https://cutt.ly/QQFdyJ8

Lanfant, M. (1980). Introducción: el turismo en el proceso de internacionalización. Revista Internacional de Ciencias Sociales, 32(1), 14-45. https://unesdoc.unesco.org/ark:/48223/pfoooo038317_spa

Lefebvre, H. (2013). La producción del espacio. Capitán Swing, S.L.

Luxemburg, R. (1978). La acumulación del capital. Grijalbo. 
Malm, A. (2016). Fossil capital: the rise of steam power and the roots of global warming. Verso.

Martoccia, H. (2010, 13 de enero). Dañan hábitat del caracol rosado en QR. LA JORNADA. https://www. jornada.com.mx/2010/01/13/estados/o26n2est

Martoccia, H. (2009, 14 de diciembre). Viola normas ambientales proyecto de recuperación de playas en QR. La Jornada. https://cutt.ly/gQFdoQw

Martínez, L. (2010). NAFTA, tourism, and environment in Mexico. International Environmental Agreements: Politics, Law and Economics, 10(2), 107-131. http://doi.org/10.1007/s10784-010-9116-8

Martínez-Alier, J. (2011). El ecologismo de los pobres. Conflictos ambientales y lenguajes de valoración. Icaria Editorial.

Martínez-Alier, J. (2006). Los conflictos ecológico-distributivos y los indicadores de sustentabilidad. Polis, Revista de la Universidad Bolivariana, 5(13), o. https://journals.openedition.org/polis/5359

Marx, C. (1999). El capital. Crítica de la economía política. Fondo de Cultura Económica.

Marx, C. (1959). El capital III. Crítica de la economía política. Fondo de Cultura Económica.

Moore, J. (2017a). Metabolic rift or metabolic shift? Dialectics, nature, and the world-historical method. Theory and Society, 46(4), 285-318. https://doi.org/10.1007/s11186-017-9290-6

Moore, J. (2017b). ¿Trabajo barato? tiempo, capital y la reproducción de la naturaleza humana. Relaciones Internacionales, (36), 215-232. http://dx.doi.org/10.15366/relacionesinternacionales2017.36.011

Moore, J. (2016). El fin de la naturaleza barata: o cómo aprendí a dejar de preocuparme por el medioambiente y amar la crisis del capitalismo. Relaciones Internacionales, (33), 143-174. https:// revistas.uam.es/index.php/relacionesinternacionales/article/view/6731

Moore, J. (2015). Capitalism in the web of life: ecology and the accumulation of capital. Verso.

Moore, J. (2014). De objeto a oikeios: la construcción del ambiente en la ecología-mundo capitalista. Revista Sociedad y Cultura, (2), 87-107.

Moore, J. (2013). El auge de la ecología-mundo capitalista I. Las fronteras mercantiles en el auge y decadencia de la apropiación máxima. Laberinto, (38), 9-26. https://dialnet.unirioja.es/servlet/ articulo?codigo $=4327593$

Moore, J. (2003): Nature and the transition from feudalism to capitalism. Review Fernand Braudel Center, 26(2), 409-433. https://www.jstor.org/stable/40241571

Muñoz, B., Gómez, J.C., y Mariscal, S. (2012). Mantenimiento correctivo, única opción para la recuperación de playas. IINGEN. http://www.iingen.unam.mx/es-mx/difusion/Lists/ElIIUNAMEnPrensa/DispForm. aspx? ID $=91$

O'Connor, J. (2001). Causas naturales. Ensayos de marxismo ecológico. Siglo XXI.

Palafox, A. (2013). El turismo como eje de acumulación. Nómadas. Revista Crítica de Ciencias Sociales y Jurídicas. 161-174. https://doi.org/10.5209/rev_NOMA.2013.42347

Palafox, A., y Dzul, R. (2014). Impacto económico de los huracanes al turismo en Quintana Roo, México. En M. Gomes, G. Herrera y D. Teles (Eds.). Temas Latino-Americanos em turismo: planejamento, ciudades, economia e cultura (157-185). Instituto da Moda.

Palafox, A. y Zizumbo, L. (2009). Distribución territorial y turismo en Cozumel, Quintana Roo, México. Gestión Turística, (11), 69-88. https://doi.org/10.4206/gest.tur.2009.n11-04

Rubí-González, F. y Palafox-Muñoz, A. (2017). El turismo como catalizador de pobreza. Trabajo turístico y precariedad en Cozumel, México. Alba Sud Editorial.

Santander, L., y Ramos-Díaz, M. (2011). El nacimiento de un destino turístico en el caribe mexicano. Cozumel, de isla abandonada a puerto de cruceros. El Periplo Sustentable, (21), 5-30. https://rperiplo. uaemex.mx/article/view/5013

Smith, N. (2008). Uneven development, capital, and the production of space. The University of Georgia Press.

Torres, A., Brandt, J., Lear, K., \& Liu, J. (2017). A looming tragedy of the sand commons. Science, 357(6355), 970-971. http://doi.org/10.1126/science.aaoo503 


\section{AUTORES}

Alejandro Escalera Briceño. Doctor en Desarrollo Sostenible (2018), Universidad de Quintana Roo. Actualmente es Profesor - Investigador en la Universidad Intercultural del Estado de Puebla en la División de Ciencias Naturales, donde dirige el Cuerpo Académico (UIEP-CA-4) Patrimonios, Turismo y Espacios Rurales. Pertenece al Sistema Nacional de Investigadores Nivel Candidato del Consejo Nacional de Ciencia y Tecnología (CONACYT) desde el año 2020.

† Alejandro Palafox Muñoz. Doctor en Ciencias Ambientales UAEMéx / Maestro en Estudios Turísticos UAEMéx / Licenciado en Turismo UAEMex. Profesor - Investigador en la Universidad de Quintana Roo. Pertenece al Sistema Nacional de Investigadores Nivel II. Miembro de la Asociación Mexicana de Investigación Turística. Miembro de la Red Latinoamericana de Investigadores en Desarrollo y Turismo.

\section{Conflicto de intereses}

Los autores informan que no existe conflicto de interés posible.

\section{Financiamiento}

No existió asistencia financiera de partes externas al presente artículo.

\section{Nota}

† Lamentamos informar que durante el proceso editorial del artículo, el Dr. Alejandro Palafox Muñoz ha fallecido. El doctor Alejandro Escalera menciona que: "él fue un hombre que nos enseñó a resistir. Querido compañero continuarás con nosotros en tus obras y en tus afectos, que la tierra te sea ligera". 